\title{
Hepatotoxic Assessment of Tramadol-Diclofenac Use: A Study in a Rat Model
}

\author{
Elias Adikwu*, Ebinyo Clemente Nelson \\ Department of Pharmacology and Toxicology, Faculty of Pharmacy, Niger Delta University, Bayelsa State, Nigeria. \\ Corresponding author* \\ adikwuelias@gmail.com
}

\begin{abstract}
The concurrent use of tramadol and diclofenac may increase hepatotoxic risk due to their individual hepatotoxic effects. This study assessed the hepatotoxic effect of tramadol-diclofenac administration in albino rats. Twenty-four adult male albino rats (200-220g) randomized into four groups were orally administered with tramadol $(12 \mathrm{mg} / \mathrm{kg} / \mathrm{day})$, diclofenac $(6 \mathrm{mg} / \mathrm{kg} / \mathrm{day})$ and tramadol-diclofenac for 14 days respectively. The rats were anesthetized, blood samples were collected and evaluated for serum liver function and lipid parameters. Liver samples were weighed and evaluated for biochemical parameters and histology. The effects of tramadol-diclofenac on the body and liver weights did not differ significantly ( $p>0.05$ ) when compared to control. Also, effects were not significant ( $p>0.05$ ) on blood glucose, and serum cholesterol, triglyceride, low and high density lipoprotein cholesterol levels when compared to control. Liver and serum levels of aminotransferases, alkaline phosphatase, lactate dehydrogenase, gamma-glutamyl transferase, conjugated bilirubin and total bilirubin increased significantly in rats treated with tramadol $(\mathrm{p}<0.05)$, diclofenac $(\mathrm{p}<0.01)$ and tramadol-diclofenac $(\mathrm{p}<0.001)$ when compared to control. Furthermore, significant decreases in liver catalase, glutathione, superoxide dismutase, glutathione peroxidase levels with significant increases in malondialdehyde levels occurred in rats treated with tramadol $(p<0.05)$, diclofenac $(p<0.01)$ and tramadol-diclofenac $(\mathrm{p}<0.001)$ when compared to control. Hepatocyte necrosis was observed in rats treated with tramadol-diclofenac. Tramadol-diclofenac may increase hepatotoxic risk at doses used for this study.
\end{abstract}

Keywords: tramadol; diclofenac; co-treatment; toxicity; liver; rat

\section{INTRODUCTION}

Most medical conditions are associated with pain. Pain remains the most inadequately treated symptom due to different cultural, attitudinal, educational, legal, and system-related reasons (Connors et al., 1995). Pain has a multifactorial origin; hence it may be difficult to achieve effective pain control with a single drug. Combination therapy with analgesics from different groups is advantageous in targeting both peripheral and central pain pathways (Rawal et al., 2011). The World Health Organization (WHO) Analgesic Ladder recommends the combination of acetaminophen or NSAIDs with opioids as the second step in the treatment of pain, based on increasing pain severity (Blondel and Azadfard, 2013).

Tramadol-diclofenac can be used for the treatment or management of chronic pain (Mitra et al., 2012). Diclofenac is a phenylacetic acid derivative which belongs to the acetic acid class of NSAIDs. It acts by inhibiting cellular cyclooxygenases (Cox-1 and Cox-2), which results to decreases in the production of proinflammatory prostaglandin, prostacyclin and thromboxane products which are important mediators of inflammation and pain (Zimmerman, 1999; Lewis and Stine, 2013). Tramadol is a synthetic codeine analog that acts as a weak opioid agonist in addition to mildly inhibiting serotonin and norepinephrine reuptake.
Tramadol is effective against mild-to-moderate pain. Clinically, tramadol-diclofenac use could advantageously target both peripheral and central pain pathways and leverage on the ability of individual drug to reduce pain and fasten recovery (Raffa, 2001). However, tramadol-diclofenac use may increase hepatotoxic risk since both drugs have hepatotoxic potential. Clinically, apparent liver injury due to diclofenac has been reported and it ranks in the top 10 causes of drug-induced liver injury (Dunk et al., 1982). Tramadol can cause respiratory arrest as well as acute liver failure, which several fatal instances reported (Loughrey et al., 2003). The use of tramadol-diclofenac calls for hepatotoxic assessment which this study evaluated in a rat model.

\section{MATERIAL AND METHODS}

\section{Animals and drugs}

Adult male albino rats of weight $200-220 \mathrm{~g}$ were used. The rats were supplied by the animal house of the Department of Pharmacology and Toxicology Niger, Delta University, Nigeria. The rats were housed in four cages ( 6 per cage) and allowed to acclimatize for 2 weeks in a well-ventilated room, maintained at a room temperature of $28 \pm 2^{\circ} \mathrm{C}$, under natural lighting condition. The rats were fed with standard rodents chow 
and given water ad libitum. Tramadol hydrochloride (ZIM laboratories Ltd India) and diclofenac potassium (Adpharm Nigeria Ltd) were used for this study. All other chemical substances used for this study are of analytical grade. Higher doses of tramadol $(12 \mathrm{mg} / \mathrm{kg} /$ day) and diclofenac $(6 \mathrm{mg} / \mathrm{kg} /$ day $)$ dissolved in normal saline were used for this study.

\section{Grouping of animals and drug treatment}

Twenty-four adult male albino rats were divided into four (4) groups A-D of 6 rats each.

- Group A (control) was orally administered with normal saline $(0.2 \mathrm{~mL})$ for 14 days.

- Group B was orally administered with tramadol (12 $\mathrm{mg} / \mathrm{kg} / \mathrm{day}$ ) for 14 days.

- Group C was orally administered with diclofenac $(6 \mathrm{mg} / \mathrm{kg} /$ day $)$ for 14 days.

- Group D was orally administered with tramadol $(12 \mathrm{mg} / \mathrm{kg} /$ day) and diclofenac $(6 \mathrm{mg} / \mathrm{kg} /$ day) for 14 days.

\section{Collection of sample}

The rats were sacrificed with inhalational diethyl ether after drug administration and blood samples were collected from the heart. At $1500 \mathrm{~g}$ for 15 minutes, the blood samples were centrifuged, serum samples extracted and evaluated for liver function parameters. Liver samples were harvested and washed in a cold $1.15 \% \mathrm{KCl}$ solution and homogenized in $0.1 \mathrm{M}$ Tris$\mathrm{HCl}$ buffer, $\mathrm{pH}$ 7.4. The homogenates were centrifuged at $1500 \mathrm{~g}$ for 15 minutes and the supernatants were decanted and evaluated for biochemical parameters.

\section{Evaluation of biochemical and oxidative stress indices}

Aspartate aminotransferase (AST), alanine aminotransferase (ALT), alkaline phosphatase (ALP), total bilirubin (TB), conjugated bilirubin (CB), gammaglutamyl transferase (GGT), lactate dehydrogenase
(LDH), total cholesterol (TC), triglyceride (TG) and high density lipoprotein cholesterol (HDL-C) were evaluated using standard laboratory test kits. Blood glucose $(\mathrm{G})$ was evaluated using glucometer while low density lipoprotein cholesterol (LDL-C) was determined using friedewald equation. Liver protein was evaluated according to Gornall et al. (1949). The method described by Sun and Zigma, (1978) was used for the evaluation of superoxide dismutase (SOD) whereas catalase (CAT) was determined according to Aebi, (1984). Glutathione (GSH) was estimated as described by Sedlak and Lindsay, (1968) whereas glutathione peroxidase (GPx) was evaluated according to the method of Rotruck, et al, (1973). Malondialdehyde (MDA) was determined as reported by Buege and Aust, (1978).

\section{Histological examination of the liver}

Liver samples were fixed in $10 \%$ neutral buffered formalin, processed and embedded in paraffin wax. Sections of $5 \mu \mathrm{m}$ thickness were cut, stained with haematoxylin and eosin and examined under a light microscope and relevant sections photographed.

\section{Statistical analysis}

Data are expressed as mean \pm SEM. Data was subjected to student $t$ test. Results were considered to be significant at $\mathrm{p}<0.05 ; 0.01 ; 0.001$.

Table 1. Effects of tramadol-diclofenac on body and liver weights of albino rats.

\begin{tabular}{llll}
\hline Groups & $\begin{array}{l}\text { Body weight } \\
\text { (g) }\end{array}$ & $\begin{array}{l}\text { Absolute liver } \\
\text { weight }(\mathbf{g})\end{array}$ & $\begin{array}{l}\text { Relative liver } \\
\text { weight }(\%)\end{array}$ \\
\hline A & $290 \pm 11.3$ & $6.03 \pm 0.13$ & $2.07 \pm 0.01$ \\
B & $295 \pm 14.2$ & $6.22 \pm 0.25$ & $2.10 \pm 0.73$ \\
C & $275 \pm 10.6$ & $5.99 \pm 0.31$ & $2.17 \pm 0.59$ \\
D & $295 \pm 11.5$ & $6.21 \pm 0.19$ & $2.10 \pm 0.77$
\end{tabular}

$\mathrm{n}=6$. Data are expressed as mean \pm SEM.

Table 2. Effects of tramadol-diclofenac on blood glucose and serum lipids of albino rats.

\begin{tabular}{llllll}
\hline Group & $\mathbf{G}(\mathbf{m g} / \mathbf{d L})$ & $\mathbf{T G}(\mathbf{m g} / \mathbf{d L})$ & $\mathbf{T C}(\mathbf{m g} / \mathbf{d L})$ & HDLC(mg/dL) & $\mathbf{L D L C}(\mathbf{m g} / \mathbf{d L})$ \\
\hline A & $95.0 \pm 6.41$ & $70.5 \pm 6.78$ & $110.1 \pm 10.8$ & $30.7 \pm 3.44$ & $65.7 \pm 6.00$ \\
B & $90.7 \pm 7.85$ & $72.1 \pm 7.59$ & $106.8 \pm 10.3$ & $31.8 \pm 3.35$ & $61.6 \pm 5.32$ \\
C & $92.0 \pm 6.42$ & $74.9 \pm 6.70$ & $112.0 \pm 10.6$ & $32.6 \pm 2.61$ & $64.5 \pm 6.42$ \\
D & $100.9 \pm 9.19$ & $81.1 \pm 7.56$ & $110.3 \pm 11.1$ & $32.4 \pm 2.63$ & $64.7 \pm 7.62$ \\
\hline
\end{tabular}

$\mathrm{n}=6$, Data are expressed as mean \pm SEM.

Table 3. Effects of tramadol-diclofenac on serum liver function indices of albino rats

\begin{tabular}{llllllll}
\hline Group & AST(U/L) & ALT(U/L) & ALP(U/L) & GGT(U/L) & $\mathbf{L D H}(\mathbf{U} / \mathbf{L})$ & $\mathbf{C B}(\mathbf{g} / \mathbf{d L})$ & $\mathbf{T B}(\mathbf{g} / \mathbf{d L})$ \\
\hline A & $41.5 \pm 5.57$ & $34.2 \pm 3.15$ & $42.3 \pm 3.56$ & $45.5 \pm 3.11$ & $0.75 \pm 1.53$ & $2.66 \pm 0.18$ & $4.21 \pm 0.05$ \\
B & $60.5 \pm 6.96^{\mathrm{a}}$ & $55.1 \pm 4.06^{\mathrm{a}}$ & $69.5 \pm 6.11^{\mathrm{a}}$ & $66.0 \pm 6.01^{\mathrm{a}}$ & $1.60 \pm 0.71^{\mathrm{a}}$ & $3.95 \pm 0.06^{\mathrm{a}}$ & $6.6 \pm 0.02^{\mathrm{a}}$ \\
C & $89.3 \pm 6.33^{\mathrm{b}}$ & $79.2 \pm 5.25^{\mathrm{b}}$ & $87.7 \pm 7.71^{\mathrm{b}}$ & $88.1 \pm 9.43^{\mathrm{b}}$ & $2.67 \pm 0.52^{\mathrm{b}}$ & $5.73 \pm 0.65^{\mathrm{b}}$ & $9.8 \pm 0.06^{\mathrm{b}}$ \\
D & $220.6 \pm 10.7^{\mathrm{c}}$ & $181.3 \pm 9.70^{\mathrm{c}}$ & $211.3 \pm 9.37^{\mathrm{c}}$ & $220.2 \pm 14.2^{\mathrm{c}}$ & $6.21 \pm 0.37^{\mathrm{c}}$ & $15.4 \pm 1.22^{\mathrm{c}}$ & $22.8 \pm 0.76^{\mathrm{c}}$ \\
\hline
\end{tabular}

$\mathrm{n}=6$, Data are expressed as mean \pm SEM, a Differ significantly at $\mathrm{p}<0.05$ when compared to control ${ }^{\mathrm{b}}$ Differ significantly at $\mathrm{p}<0.01$ when compared to control, ${ }^{\mathrm{c}}$ Differ significantly at $\mathrm{p}<0.001$ when compared to control. 
Table 4. Effects of tramadol-diclofenac on liver tissue biochemical parameters of albino rats.

\begin{tabular}{llllll}
\hline Group & AST(U/L) & ALT(U/L) & ALP(U/L) & GGT(U/L) & LDH(U/L) \\
\hline A & $244.8 \pm 12.0$ & $246.9 \pm 12.1$ & $247.2 \pm 12.3$ & $250.5 \pm 14.2$ & $22.9 \pm 4.03$ \\
B & $373.8 \pm 17.6^{\mathrm{a}}$ & $374.6 \pm 20.4^{\mathrm{a}}$ & $390.0 \pm 20.0^{\mathrm{a}}$ & $399.0 \pm 17.4^{\mathrm{a}}$ & $45.2 \pm 7.09^{\mathrm{a}}$ \\
C & $499.6 \pm 25.0^{\mathrm{b}}$ & $470.3 \pm 26.0^{\mathrm{b}}$ & $488.4 \pm 23.4^{\mathrm{b}}$ & $475.1 \pm 21.2^{\mathrm{b}}$ & $68.1 \pm 8.16^{\mathrm{b}}$ \\
D & $960.0 \pm 23.7^{\mathrm{c}}$ & $983.3 \pm 41.8^{\mathrm{c}}$ & $901.0 \pm 43.7^{\mathrm{c}}$ & $888.2 \pm 30.6^{\mathrm{c}}$ & $190.5 \pm 12.8^{\mathrm{c}}$ \\
\hline
\end{tabular}

$\mathrm{n}=6$, Data are expressed as mean $\pm \mathrm{SEM}$, ${ }^{\text {a }}$ Differ significantly at $\mathrm{p}<0.05$ when compared to control ${ }^{\mathrm{b}}$ Differ significantly at $\mathrm{p}<0.01$ when compared to control, ${ }^{\mathrm{c}}$ Differ significantly at $\mathrm{p}<0.001$ when compared to control

Table 5. Effect of tramadol-diclofenac on liver oxidative stress indices of albino rats.

\begin{tabular}{llllll}
\hline Group & $\begin{array}{l}\text { MDA } \\
\text { (nmol/mg } \\
\text { protein) }\end{array}$ & $\begin{array}{c}\text { SOD } \\
(\mathbf{U} / \mathbf{m g} \text { protein) }\end{array}$ & $\begin{array}{l}\text { CAT } \\
(\mathbf{U} / \mathbf{m g} \text { protein) }\end{array}$ & $\begin{array}{l}\text { GSH } \\
(\boldsymbol{\mu m o l} / \mathbf{m g} \\
\text { protein) }\end{array}$ & $\begin{array}{c}\text { GPx } \\
(\mathbf{U} / \mathbf{m g} \text { protein })\end{array}$ \\
\hline A & $0.17 \pm 0.06$ & $16.2 \pm 1.89$ & $26.4 \pm 2.77$ & $8.96 \pm 0.15$ & $11.7 \pm 0.16$ \\
B & $0.39 \pm 0.04^{\mathrm{a}}$ & $11.6 \pm 0.15^{\mathrm{a}}$ & $17.0 \pm 0.79^{\mathrm{a}}$ & $5.02 \pm 0.32^{\mathrm{a}}$ & $5.25 \pm 0.01^{\mathrm{a}}$ \\
C & $0.52 \pm 0.04^{\mathrm{b}}$ & $9.98 \pm 0.04^{\mathrm{b}}$ & $13.6 \pm 1.16^{\mathrm{b}}$ & $3.91 \pm 0.73^{\mathrm{b}}$ & $4.00 \pm 0.18^{\mathrm{b}}$ \\
D & $1.37 \pm 0.32^{\mathrm{c}}$ & $3.63 \pm 0.06^{\mathrm{c}}$ & $5.61 \pm 0.83^{\mathrm{c}}$ & $1.30 \pm 0.22^{\mathrm{c}}$ & $2.57 \pm 0.82^{\mathrm{c}}$ \\
\hline
\end{tabular}

$\mathrm{n}=6$, Data are expressed as mean $\pm \mathrm{SEM}$, ${ }^{\mathrm{a}}$ Differ significantly at $\mathrm{p}<0.05$ when compared to control ${ }^{\mathrm{b}}$ Differ significantly at $\mathrm{p}<0.01$ when compared to control, ${ }^{\mathrm{c}}$ Differ significantly at $\mathrm{p}<0.001$ when compared to control
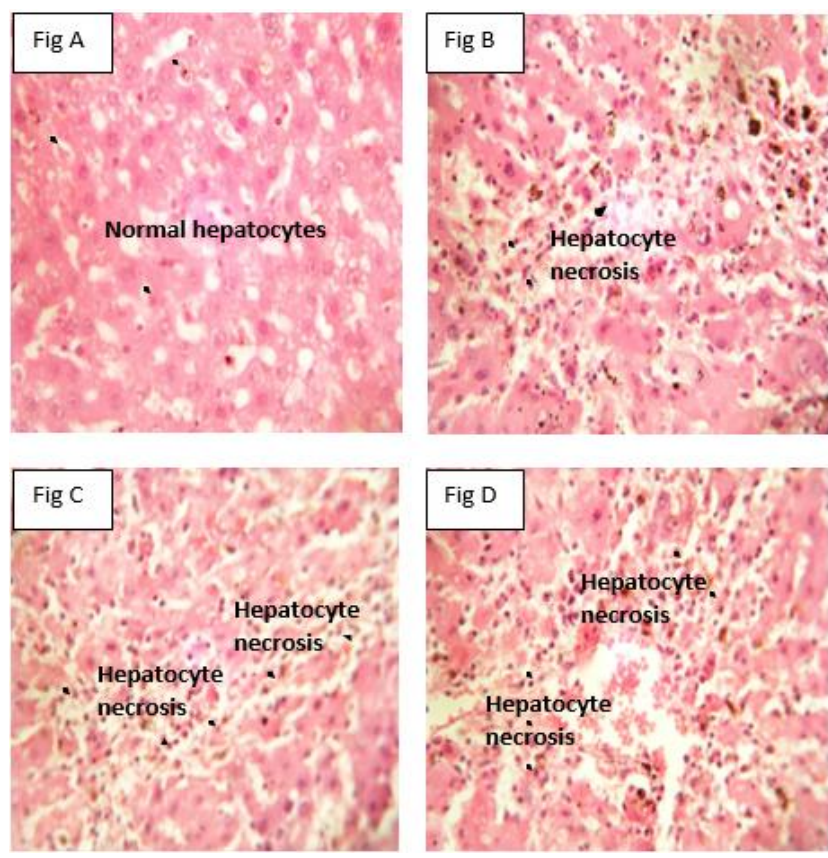

Figure 1. (A-E) showed the liver of control rat, rats treated with diclofenac, tramadol and diclofenac-tramadol (H \&E stain 400x). (A): The liver of control rat showing normal hepatocytes (B): Liver of rat treated with tramadol (12 mg/kg/day) showing hepatocyte necrosis $(\mathbf{C})$ : Liver of rat treated with diclofenac $(6 \mathrm{mg} / \mathrm{kg} /$ day) showing hepatocyte necrosis. (D): Liver of rat treated with diclofenac-tramadol showing hepatocyte necrosis

\section{RESULTS}

The effects of tramadol-diclofenac were not significant ( $>0.05)$ on the body and liver weights of treated rats when compared to control (Table 1). Also, serum TC, TG, HDL cholesterol, LDL cholesterol and blood G levels were normal $(p>0.05)$ in rats treated with tramadol- diclofenac when compared to control (Table 2). Serum AST, ALP, ALT, GGT, LDH, CT and TB levels were significantly increased in tramadol $(p<0.05)$ and diclofenac $(p<0.01)$ treated rats when compared to control. However, elevations in the serum levels of the aforementioned parameters were most significant $(\mathrm{p}<0.001)$ in rats treated with tramadol-diclofenac when compared to control (Table 3). The liver levels of AST, ALP, ALT, GGT and LDH were significantly increased in rats treated with tramadol $(\mathrm{p}<0.05)$ and diclofenac $(\mathrm{p}<0.01)$, but significant increases occurred at $\mathrm{p}<0.001$ in rats treated with tramadol-diclofenac when compared to control (Table 4). Furthermore, liver SOD, CAT, GSH and GPx levels were significantly decreased whereas MDA levels were significantly increased in rats treated with tramadol $(\mathrm{p}<0.05)$, diclofenac $(\mathrm{p}<0.01)$ and tramadol-diclofenac $(\mathrm{p}<0.001)$ when compared to control (Table 5). The liver of control rat showed normal hepatocytes (Fig A) whereas the liver of rat treated with tramadol and diclofenac showed hepatocyte necroses respectively (Fig $\mathbf{B}$ and $\mathbf{C}$ ). The liver of rats treated with tramadol-diclofenac also showed hepatocyte necrosis (Fig D).

\section{DISCUSSION}

The present study evaluated the hepatotoxic effect of tramadol-diclofenac in a rat model. The indices evaluated in this study are useful parameters to indicate impairment in the functional capacity of the liver. Analysis of organ weight in toxicology studies is an important endpoint for the identification of potentially harmful effects of chemicals. It is one of the most sensitive drug toxicity indicators, and its changes often precede morphological changes (Bailey et al., 2004). In 
the present study, tramadol-diclofenac had no effects on the body and liver weights of treated rats. Serum ALP, AST, ALT, GGT, and LDH are excellent biomarkers of hepatocellular injury. AST and ALT participate in gluconeogenesis by catalyzing the transfer of amino groups from aspartic acid or alanine to ketoglutaric acid to produce oxaloacetic acid and pyruvic acid respectively. AST is present in cytosolic and mitochondrial isoenzymes and is found in the liver while ALT, a cytosolic enzyme is found in its highest concentration in the liver and is more specific to the liver. ALP is found histochemically in the microvilli of bile canaliculi and on the sinusoidal surface of hepatocytes (Rosalki and Mcintyre, 1999). GGT is a microsomal enzyme that is abundant in hepatocytes and biliary epithelial cells. It is involved in the transfer of $\gamma-$ glutamyl groups from peptides to amino acids and the metabolism of glutathione conjugates (Friedman et al., 1996). These liver biomarkers are usually released into circulation causing elevated serum levels with the advent of hepatocellular injury (Yousef et al., 2010). This study observed elevated serum and liver levels of ALP, AST, ALT, GGT, and LDH in rats treated with tramadol-diclofenac which is a sign of hepatotoxicity. Bilirubin is an endogenous anion derived from the regular degradation of haemoglobin from the red blood cells and excreted from the liver in the bile (Saukkonen et al., 2006). Toxic insult to the liver can impair its excretory capacity to dispose bilirubin stimulating serum accumulation (Gaw et al., 1999; Jain et al., 2008). This study observed elevated serum CB and TB levels in rats treated with tramadol-diclofenac.

The anti-oxidative defense system which includes SOD, CAT, GSH and GPx is necessary for the maintenance of redox homeostasis in organisms. It terminates or prevents free radicals such as reactive oxygen species (ROS) from incapacitating the functions of biomolecules through oxidative stress (OS) (Borković et al., 2005). However, the functions of anti-oxidative system can be surmounted or incapacitated via depletion by over whelming actions of free radicals. This study observed hepatic depletions of SOD, CAT, GSH and GPx in rats treated with tramadol-diclofenac. This is an evidence which shows that OS is a factor in hepatotoxicity induced by tramadol-diclofenac. Lipid peroxidation (LPO) is an oxidative degradation of polyunsaturated fatty acids which can cause impairment in membrane structure and function. MDA level which is an important indicator of LPO can indirectly reflect the extent of hepatic LPO in-vivo and in-vitro (Jafari et al., 2012). In this study, hepatic MDA levels were increased in rats treated with tramadol-diclofenac. This observation attests to the involvement of LPO in hepatotoxicity induced by tramadol-diclofenac. Furthermore, the current study observed hepatocyte necrosis in rats treated with tramadol-diclofenac which correlates with changes observed in evaluated biochemical parameters. This study was able to show that tramadol-diclofenac use may increase the risk of hepatotoxicity. The use of diclofenac has been associated with hepatotoxicity (Hussein et al., 2016) and hepatic OS (Das and Roy, 2012) which is consistent with findings in this study. The exact mechanism by which diclofenac causes hepatotoxicity is not well understood, but diclofenac is metabolized in the liver (Castel et al., 1997) and its hepatotoxic effect has been related to its metabolites (4hydroxy 3 diclofenac, 5 hydroxy 4 diclofenac and 5 hydroxy 6 diclofenac) (Tang et al., 1999). Also, studies have associated tramadol with hepatotoxicity (El-Wessemy, 2008) characterized by OS (Rukhshanda et al., 2014) which is in agreement with observation in the present study. The mechanism by which tramadol causes hepatotoxicity is not fully known, but studies have speculated that tramadol and/or its active metabolite can stimulate hepatic ROS production leading to OS and hepatic biomolecular damage (Singal et al., 1998).

\section{CONCLUSION}

Tramadol-diclofenac use may be associated with hepatotoxicity at the doses use for this study.

\section{Conflict of interest: None}

\section{REFERENCES}

Aebi H. Catalase in vitro, in Method in Enzymology, S. P. Colowick and N. O. Kaplane, Eds., 1984; Academic Press, New York, NY, USA.

Bailey AS, Zidell RH, and Perry RW. (2004). Relationships Between Organ Weight and Body/BrainWeight in the Rat: What Is the Best Analytical Endpoint? Toxicologic Pathology, 32:448-466,

Blondel RD L, (2013). Azadfard M, Wisniewski AM. Pharmacologic Therapy for Acute Pain Am Fam Physician, 87: 766-772.

Borković S S, Šaponjić JS, Pavlović S Z, Blagojević DP, Milošević S M, Kovačević TB et al. (2005). The activity of antioxidant defence enzymes in the mussel Mytilusgalloprovincialis from the Adriatic Sea. Comp. Bioch Physiol, 141: 366 - 374.

Buege J A and Aust S D. (1978). Microsomal Lipid Peroxidation. Methods Enzymol.52: 302-310

Castel JV, Gomez-Lechon, M J, Ponsoda X, Bort R (1997). The use of cultured hepatocytes to investigate the mechanism of drug hepatotoxicity. Cell Biol. Toxicol., (Review),13: 331338

Connors AF Jr, Dawson NV, Desbiens NA (1995). A controlled trial to improve care for seriously ill hospitalized patients. The study to understand prognoses and preferences for outcomes and risks of treatments (SUPPORT).The SUPPORT Principal Investigators. JAMA. 1995; 274: 1591-1598

Dubinsky RM, MiyasakiJ. (2010). Assessment: efficacy of transcutaneous electric nerve stimulation in the treatment of pain in neurologic disorders (an evidence-based review): 
report of the Therapeutics and Technology Assessment Subcommittee of the American Academy of Neurology. Neurology, 74: 173-6.

Dunk AA, Walt RP, Jenkins WJ, Sherlock SS, (1982). Diclofenac hepatitis. Br. Med. J. 284: 160-166

El-Wessemy A M. (2008). Histopathological and ultra-structural studies on the side effects of the analgesic drug tramadol on the liver of albino mice. Egypt. J. Zool. 50: 423-442

Friedman LS, Martin P, Munoz SJ. (1996). Liver function tests and the objective evaluation of the patient with liver disease. In: Zakin D, Boyer TD, editors. Hepatology: A Textbook of Liver Disease. third ed. WB Saunders; Philadelphia: pp.791833

Gaw A, Cowan RA, O'Reilly D St. J, Stewart MJ, Shepherd J. Clinical biochemistry an illustrated colour text. 2nd ed. Edinburgh: Harcourt Brace; 1999. p. 165

Gornall A G, Bardawill C J and David M M. (1949). Determination of serum proteins by means of the biureto reaction. J. Biol. Chem. 177; 751-766.

Hussein AA, Hussein MA, Gaba EA Ahmed MR (2016). Hepatoprotective Effects of Cranberry Extract against Diclofenac Sodium Induced Liver Toxicity in Rats Int $\mathbf{J}$ Pharma Sci 6: 1447-1453

Jafari M, Salehi M, Ahmadi S, Asgari A, Abasnezhad M, Hajigholamali M. (2012). The role of oxidative stress in diazinon-induced tissues toxicity in Wistar and Norway rats.Toxicol Mech Methods, 22:638-47.

Jain R, Nandakumar K, Srivastava1 V, Vaidya SK, Patet S, Kumar P. (2008). Hepatoprotective activity of ethanolic and aqueous extract of Terminalia belerica in rats. Pharmacol onli $2: 411 ; 427$

Loughrey MB, Loughrey CM, Johnston S, O'Rourke D. (2003). Fatal hepatic failure following accidental tramadol overdose. Forensic Sci Int, 134: 232-3.

Mitra S, Khandelwal P, Sehgal A. (2012). Diclofenac-tramadol vs. diclofenac-acetaminophen combinations for pain relief after caesarean section. Acta Anaesthesiol Scand. 56:706-11.

Raffa RB. (2001). Pharmacology of oral combination analgesics: rational therapy for pain. J Clin Pharm Ther. 26(4): 257-264.

Rawal N, Macquaire V, Catalá E, Berti M, Costa R, Wietlisbach M. (2011). Tramadol/paracetamol combination tablet for postoperative pain following ambulatory hand surgery: a double-blind, double-dummy, randomized, parallel-group trial. J Pain Res. 4:103-110.

Rosalki SB, Mcintyre N. Biochemical investigations in the management of liver disease. Oxford textbook of clinical hepatology, 2nd ed. New York; Oxford university press, 1999; 503-521.

Rotruck JT, Rope AL, Ganther HF, Swason AB. (1973). Selenium: biochemical role as a component of glutathione peroxidase. Science, 179:588-90

Rukhshanda S, Razia I, Muhammad NA, Anum Z, Javed I and Muhammad SA. (2014). Effects of tramadol on histopathological and biochemical parameters in mice (Musmusculus) model.Global J Pharmacol.1:14-19.

Saukkonen JJ, Cohn DL, Jasmer RM, Schenker S, Jereb JA, et al. (2006). An Official ATS Statement: Hepatotoxicity of antituberculosis therapy. Am J RespirCrit Care Med, 174: 935-952.

Sedlak J and Lindsay RH. (1968). Estimation of Total, ProteinBound, and Nonprotein Sulfhydryl Groups in Tissue with Ellman's Reagent. Anal Biochem, 25: 1192-1205

Singhal PC, Sharma P, Kapasi AA, Reddy K, Franki N and Gibbons N. (1998). Morphine enhances macrophage apoptosis. Jour. of Immunology, 160: 1886-1893

Sun M and Zigma S. (1978). AnImprovedSpectrophotometer Assay of Superoxide Dismutase Based On Epinephrine Antioxidation. Anal Biochem. 90: 81-89

Tang W, Stearns RA, Bandiera SM, Zhang Y, Raab C, Braun MP, Dean DC, et al. (1999). Studies on cytochrome P-450mediated bioactivation of diclofenac in rats and in human hepatocytes: Identification of glutathione conjugated metabolites. Drug Metab.Dispos. 27: 365-372.

Yousef MI, Omar SA, El-Guendi MI, Abdelmegid LA. (2010). Potential protective effects of quercetin and curcumin on paracetamol-induced histological changes, oxidative stress, impaired liver and kidney functions and haematotoxicity in rat Food Chem Toxicol, 48; 3246-3261

Zimmerman HJ. (1999). Drugs used to treat rheumatic and musculospastic disease. The NSAIDS.In, Zimmerman HJ. Hepatotoxicity: the adverse effects of drugs and other chemicals on the liver. 2nd ed. Philadelphia: Lippincott, pp. 1999; 517-41. 